\title{
Judicialização dos benefícios de prestação continuada e impactos simbólicos na cidadania
}

\author{
Judicialization of continuous cash benefit and \\ symbollic impacts on citizenship
}

Julia Maurmann Ximenes*

\section{Resumo}

Os impactos da judicialização das políticas públicas têm sido objeto de muito debate acadêmico. Contudo, esse fenômeno tem aberto uma possibilidade de dar voz a atores que não conseguem ter suas demandas atendidas pelos atores políticos, como no caso da judicialização do Benefício de Prestação Continuada (BPC). A partir da análise do BPC, percebe-se os impactos simbólicos da judicialização na cidadania inclusiva, considerando que uma maior parcela da população em situação de vulnerabilidade está sendo alcançada a partir da compreensão da realidade dos sujeitos de direitos envolvidos.

Palavras-chave: Judicialização das políticas públicas. Assistência social. Benefício de prestação continuada. Sujeitos de direitos. Cidadania

\section{Abstract}

The impacts of the judicialization of public policies has been the subject of much academic debate. However, this phenomenon has opened a possibility of giving "voice" to actors who fail to have their demands met by political actors such as the the judicialization of the Continuous Cash Benefit. From the BPC analysis, we can see the symbolic impact of judicialization on inclusive citizenship, considering that a larger share of the population in a vulnerable situation is being achieved by understanding the reality of the right-holders involved.

Keywords: Judicialization of public policies. Social assistance. Continuous cash benefit. Right-holders. Citizenship.

Advogada. Doutora em Sociologia. Pós-Doutora em Direito. Professora do Programa de Mestrado em Direito Constitucional do Instituto Brasiliense de Direito Público. Brasília - Distrito Federal Brasil. E-mail: juliaximenes@idp.edu.br 


\section{Introdução}

A judicialização da política pode ser definida basicamente pela transferência de local de debate: temas tipicamente políticos passam a ser discutidos no âmbito do Poder Judiciário, não se restringindo mais apenas às esferas do Executivo e do Legislativo. Trata-se de um fenômeno irreversível, uma realidade pós-Segunda Guerra Mundial e de forte presença nos países que sofreram períodos de ditadura durante a segunda metade do século $\mathrm{XX}$, como forma de resgatar $\mathrm{o}$ Estado de Direito, depositando no Direito e no Poder Judiciário grande responsabilidade na construção do Estado Democrático de Direito. ${ }^{1}$

Além disso, o movimento de constitucionalização do Direito aumentou ainda mais a força do Direito, especialmente o constitucional, depositando nele uma crença ingênua de transformar a realidade pela positivação de direitos - exemplo típico é a Constituição de 1988 e toda a discussão sobre seu caráter dirigente ou programático dos direitos sociais. Este debate acarretou uma nova percepção sobre o compromisso do Direito - com o conteúdo das normas e sua efetividade. A discussão, de cunho sociojurídico, ultrapassa a previsão normativa e o debate sobre o papel do Poder Judiciário, avançando para a presença do Direito nas relações sociais, para novas possibilidades e espaços de discussão sobre temas políticos. ${ }^{2}$

\footnotetext{
Para aprofundar ver: PACHECO, Cristina C. Os estudos sobre judiciário e política no Brasil pós 1988: uma revisão de literatura. Pensar, Fortaleza, v. 13, n. 1, p. 75-86, jan./jun. 2008; BARROSO, Luís Roberto. Judicialização, ativismo judicial e legitimidade democrática. Disponível em: $<w w w$. direitofranca.br/direitonovo/FKCEimagens/file/ArtigoBarroso_para_selecao.pdf>; MACIEL, Débora Alves; KOERNER, Andrei. Sentidos da judicialização da política: duas análises. Lua Nova, São Paulo, n. 57, 2002, p. 113-133; CITTADINO, Gisele. Judicialização da política, constitucionalismo democrático e separação de poderes. In: VIANNA, Luiz Werneck (Org.). A democracia e os três poderes no Brasil. Belo Horizonte: UFMG, 2002, p. 17-39; CARVALHO, Ernani Rodrigues de. Em busca da judicialização da política no Brasil: apontamentos para uma nova abordagem. Revista de Sociologia Política, Curitiba, v.23, p. 115-126, nov. 2004; YEPES UPRIMNY, Rodrigo. Ajudicialização da política na Colômbia: casos, potencialidades e riscos. SUR - Revista Internacional de Direitos Humanos, ano 4, n. 6, p. 52-69, 2007.

2 "What is clear is that political authority has everywhere given judicial authority the responsability, expressly or by default, to protect the rights of citizens, police separation of power schemes, and check bureaucratic discretion. Elected officials, lobbysts, and citizens' action groups have in turn been provided with new arenas (law and courts) for pressing their political claims. These developments reflect, or translate into, a very widespread increase in the prestige and self-confidence of the judiciary" (SHAPIRO; STONE, 1994, p. 402).
} 
Desse cenário foi fácil partir para um novo fenômeno, o da ampliação da judicialização da política para o da judicialização das políticas públicas. Ou seja, o cidadão busca o Poder Judiciário para efetivar questões sociais, típicas de políticas públicas. Aqui exemplos como saúde (o mais significativo no caso brasileiro), assistência social, educação, meio ambiente, segurança pública, dentre outros.

A proposta do presente artigo está inserida neste contexto e ciente do leque de críticas a atuação do Poder Judiciário na efetivação de direitos sociais. A análise sobre a legitimidade da atuação do Poder Judiciário na efetivação de direitos sociais é extensa e objeto de muita controvérsia. As críticas incluem o papel do Poder Judiciário na relação com os demais poderes estritamente políticos e responsáveis pela definição de políticas públicas ${ }^{3}$, pela necessidade de "pragmaticidade dos direitos fundamentais" (GALDINO, 2005) e as injustiças no próprio acesso à Justiça ${ }^{4}$, e pela eventual diminuição da autonomia individual e desmobilização popular. ${ }^{5}$

3 Neste sentido, a própria atuação seria compreendida como ativismo judicial, no que Streck (2011, p. 72) aponta que "tem sido pratico às avessas em terrae brasilis, contribuindo para a inefetividade dos direitos fundamentais sociais." Isto porque ainda que ao demandar individualmente o efeito perverso da atuação do Poder Judiciário é justamente o impacto na política pública - "A pedra de toque estará no reconhecimento, pelo Judiciário, de que seu papel não é - nem nunca poderá ser - substitutivo, mas sim de indução do desenvolvimento regular, elas estruturas institucionais previstas na constituição, dos misteres de cada qual." (VALLE, 2009, p. 153, grifo no original).

4 Outra perspectiva crítica é a orçamentária - os "direitos não nascem em árvores" conforme aponta Galdino (2005) e o Poder Judiciário não pode ignorar a execução de decisões com forte impacto orçamentário, principalmente quando elas são individuais, pois ainda que atendam a demanda do sujeito de direito individualmente, o impacto será coletivo, uma tensão entre "micro justiça" (Justiça Comutativa) e "macro justiça" (Justiça Redistributiva), pois a "justiça distributiva não pode fazer-se levando em conta o esquema bilateral" (LOPES, 2006, p. 135). Ferraz (2011) aponta que na verdade a judicialização da saúde acaba penalizando o pobre que não tem acesso a advogados e consequentemente a Justiça.

5 Este é o principal argumento da ciência política - a criação de uma "cidadania clientelista". "E o resultado disso é que o cidadão individualizado não mais se envolve em questões de mobilização social e a justiça se torna um verdadeiro balcão de queixas sociais". (GONÇALVES, 2006, p. 95). Aqui o grande risco da expansão da atuação do Poder Judiciário: um governo de juízes. "A justiça não pode se colocar no lugar da política; do contrário, arrisca-se a abrir caminho para uma tirania das minorias, e até mesmo para uma espécie de crise de identidade. Em resumo, o mau uso do direito é tão ameaçador para a democracia como seu pouco uso."(GARAPON, 2001, p. 53). Uma espécie de "superego da sociedade" cerceando a autonomia dos indivíduos e a soberania popular (MAUS, 2000). 
Ciente da relevância dessas questões, cumpre salientar que o presente trabalho, entretanto, não busca "defender" nenhuma abordagem específica mas sim apresentar uma possibilidade de análise de um caso de judicialização da política pública a partir de um paradigma diferenciado - o da visibilidade de sujeitos de direitos, ou seja, da inclusão de indivíduos em uma sociedade desigual como a brasileira. ${ }^{6}$

O objetivo é relacionar, através do estudo de um caso, a judicialização das políticas públicas e o atual arranjo democrático brasileiro $^{7}$, tendo como paradigma a cidadania inclusiva em uma sociedade desigual. ${ }^{8} \mathrm{O}$ Poder Judiciário brasileiro, sozinho, não será o "salvador da pátria" (KRELL, 2002, p. 109), mas suas decisões poderão contribuir na efetivação dos direitos sociais e o presente trabalho busca refletir a partir desta perspectiva.

Isto porque nossa preocupação reside nos impactos indiretos e simbólicos. Conforme aponta Rodríguez-Garavito (2011), a discussão sobre a judicialização dos direitos econômicos, sociais e culturais (DESC) tem se concentrado em duas dimensões: a) a acionabilidade dos DESC a partir de teorias democráticas em contextos de realidade social marcada por desigualdade econômica e política; b) sob a perspectiva da doutrina dos direitos humanos. Apesar da relevância sobre o debate

6 Independentemente da discussão sobre um eventual Estado Social no Brasil, o importante é resgatar o papel dos direitos sociais na lógica da solidariedade como pressuposto para as relações sociais que o Welfare State acarreta (EWALD, 1986).

$7 \quad$ Nas palavras de Victor Abramovich (2005, p.201): "Cabe dar razão a algumas das tradicionais objeções efetuadas nessa matéria: o Poder Judiciário é o menos indicado para realizar planejamentos de política pública; a ação judicial é um meio pouco apropriado para discutir medidas de alcance geral; a discussão processual gera problemas de desigualdade em relação ás pessoas afetadas pelo mesmo descumprimento que não participaram da ação; o Poder Judiciário carece de meios compulsório para a execução forçada de uma suposta sentença que condene o Estado a cumprir uma prestação que havia sido omitida para todos os casos envolvidos ou para editar a regulamentação omitida; a substituição de medidas gerais por decisões ad hoc efetuadas pelo juiz no caso particular pode ter também como resultado desigualdades indesejáveis; etc.."

8 "E é no "engajamento" que reside a hipótese aqui apresentada sobre o resgate dos 'sujeitos de direitos': a cidadania inclusiva. Os direitos sociais, principalmente os direitos relacionadas a proteção social, especificamente os da assistência social, recebem ainda críticas no sentido de serem um 'benefício aos necessitados', uma compreensão típica da racionalidade liberal que não está presente na ordem constitucional brasileira atual." (XIMENES, 2015, p. 90). 
teórico, pouco tem se estudado sobre a implementação das decisões e seus impactos. O que acontece com as decisões e qual o seu impacto no Estado, na sociedade civil, nos movimentos sociais e na opinião pública?

Esta problematização conduzirá o presente trabalho, mas relacionada com o arranjo democrático: em que medida a judicialização de uma política pública de cunho assistencial, o Benefício de Prestação Continuada (BPC), se relaciona com a efetivação da cidadania inclusiva? Para a presente análise, a judicialização das políticas públicas será valorizada por intermédio da categoria operacional da cidadania em uma perspectiva de acesso à Justiça, de sujeitos de direitos (inclusão social) ${ }^{9}$ e de empoderamento ${ }^{10}$.

O pressuposto mais amplo é a compreensão da necessidade atual do Estado Brasileiro de debater o papel da proteção social na ampliação da solidariedade e da inclusão social, por intermédio da garantia de rendas mínimas nas diversas situações de vulnerabilidade social e pobreza: "O pressuposto de tal garantia [proteção social] é a existência de um compromisso entre diferentes setores da sociedade em torno da implantação de um regime de solidariedade garantido pelo Estado e tendo como objetivo a redução da vulnerabilidade, da insegurança e do risco da pobreza" (JACCOUD, 2009, p. 19).

A hipótese é que após o período de consolidação democrática, o Brasil precisa resgatar os "sujeitos de direitos" em suas análises sobre a litigância e os efeitos simbólicos desta na cidadania.

9 Conforme destaca Oscar Vilhena Vieira (2008, p. 201): "Ao traduzir uma demanda social em uma demanda jurídica nos descolamos de um ambiente de competição por puro poder para um processo no qual as decisões devem ser justificadas em termos jurídicos. A necessidade de justificativa legal reduz o espaço de pura discricionariedade. Nessas circunstâncias, o sistema jurídico pode dar visibilidade pública, na forma de reconhecimento de direitos àqueles que são desconsiderados pelo sistema politico e pela própria sociedade."

10 "Empoderamento" tem origem inglesa, empowerment, e pode ser traduzido como fortalecimento, e a partir da autonomia e emancipação de indivíduos submetidos a relações de tutela e poder. Isto porque o "sujeito de direito" aqui é o right-holder, que literalmente significa "detentor do direito" o que não expressa o significado aqui utilizado. Isto porque não estamos tratando apenas da previsão normativa de direitos a "sujeitos", mas sim a capacidade destes sujeitos de exercer estes direitos. 
Para tanto, iniciaremos com a apresentação do referencial teórico para a análise do caso. Em seguida, apresentaremos o histórico da judicialização do Benefício de Prestação Continuada, benefício de assistência social previsto constitucionalmente. Por fim, analisaremos o caso retomando a grade de leitura, buscando comprovar nossa hipótese: a judicialização da política pública no caso do BPC é um instrumento de concretização da cidadania, propiciando um novo arranjo democrático, favorável a inclusão de parcela da população, dando voz (GLOPPEN, 2006) e/ou tornando visível (VIEIRA, 2008) parcela da população excluída do debate sobre os direitos sociais, normalmente restrita a perspectiva de "beneficiários". ${ }^{11}$

\section{Referencial teórico de análise}

O fenômeno da judicialização das políticas públicas se insere em um contexto de crise e reflexão sobre a eficácia do Direito Positivo à luz da Sociologia Jurídica. Apesar da resistência, o campo jurídico cada vez mais tem considerado elementos não exclusivamente normativos para a solução de seus problemas. Esta ideia decorre da necessária conexão disciplinar entre a visão sociológica e a perspectiva jurídica sobre o papel do Direito, mais especificamente a Constituição e o Poder Judiciário, na efetivação da igualdade. ${ }^{12}$

A discussão jurídica tem se concentrado no debate entre a teoria da constituição dirigente e a teoria constitucional democrático-deliberativa. A primeira se concentra na necessidade do procedimento democrático para a realização da justiça social e na "força normativa da constituição", inclusive dotando o sistema jurídico de instrumentos processuais para a concretização do programa constitucional pelo Poder Judiciário, como

\footnotetext{
11 Importante registrar que a proposta aqui é justamente resistir ao discurso do assistencialismo: as políticas de assistência social perpassam direitos constitucionais e não "caridade" ou "doação" por parte do Estado.

12 "La desconexión disciplinaria entre lavisión sociológica y la perspectiva jurídica es, a mi juicio, lafuente de muchos problemas em América Latina, empezando por la existencia de políticas públicas sin fundamento, hasta llegas a um entendimento idealizado y formalista de la dogmática jurídica, pasando por laconformación de um pensamiento crítico miope y simplista sobre elderecho y las realidades jurídicas." (VILLEGAS, 2010, p. 12).
} 
é o caso da ação de inconstitucionalidade por omissão (SOUZA NETO, 2012, p. 13-16). ${ }^{13}$

A teoria constitucional democrático-deliberativa destaca a democracia como condição, e não como fim, cabendo às constituições estabelecerem apenas a estrutura básica do Estado Democrático de Direito. O papel do Poder Judiciário é controlar a violação de direitos fundamentais pelas maiorias eventuais, restringindo-se ao campo da imparcialidade política (SOUZA NETO, 2012, p. 22).

A partir das duas teorias, surge a pergunta: qual é o papel do Poder Judiciário que se almeja? Ele deverá ser guardião do conteúdo do Estado Democrático de Direito ou apenas do direito positivo "formal"? O problema não é apenas medir o acesso dos cidadãos à justiça, mas abrir novas perspectivas na definição da própria Justiça. Aqui adentramos nossa categoria operacional: a cidadania.

No entanto, o desafio atual não é alargar os direitos - ou elaborar declarações de direitos (por mais importantes que estas sejam para os advogados constitucionalistas e para o simbolismo político) - mas encontrar meios e recursos para tornar, tanto 'efetivos', quando 'coativos', os direitos que os cidadãos já têm. Somente por meio da aplicação de rigorosos procedimentos acadêmicos à natureza, ao escopo e ao papel dos sistemas judiciais civis no provimento dos direitos abstratos frequentemente exaltados na retórica legal será possível expor a deficiência e a hipocrisia que cercam o discurso constitucional. (ECONOMIDES, 1999, p. 71).

Na mesma linha, Abromovich (2005, p. 209) resgata que a atuação judicial pode ser conceituada como a participação em um "diálogo" entre os distintos poderes do Estado para a concretização do programa jurídico-político previsto na Constituição, e acrescenta:

13 "Em nosso País, essa perspectiva acabou resultando em um movimento político-teórico que podemos denominar 'constitucionalismo brasileiro da efetividade'." (SOUZA NETO, 2012, p. 8). Três características do texto constitucional são apontadas como principais ao seu potencial emancipatório: o extenso rol de direitos sociais, "complexo aparato de garantia das liberdades individuais", e típica Constituição Dirigente, formulando projeto de futuro. (p. 10) 
Às vezes, as vias legais resguardam ou tornam efetivas as 'conquistas' obtidas no plano político. No marco de nossas frágeis democracias, a sanção de leis pelo Congresso nem sempre assegura a efetividade dos direitos reconhecidos e, como vimos, às vezes é necessário entrar em litígio para conseguir a implementação e o cumprimento dessas normas. Dessa forma, em um sistema institucional com fortes falhas, nem as vitórias judiciais em matéria de direitos sociais nem os triunfos políticos são definitivos, e impõem a utilização de todos os meios de reivindicação e de ação disponíveis.

A questão aqui é o alcance da reivindicação via arena judicial e sua relevância ou não para o arranjo democrático. Nesta perspectiva, o direito constitucional à jurisdição, ou seja, o direito de buscar a prestação estatal para fazer valer direitos e, portanto, solucionar conflitos havidos na sociedade. "Quanto mais democrático o povo, mais alargada é nele a jurisdição, mais efetiva, rápida, facilitada e concretizada a sua prestação" (ROCHA, 1993, p. 32). Trata-se de direito-garantia do cidadão:

Ao cidadão confere-se a jurisdição como um direito cujo exercício dignifica o próprio titular. Este direito torna o cidadão ativo em face dos demais indivíduos e do próprio Estado, não permitindo que os seus direitos sejam lesados ou comprometidos por ação de outrem sem a correspectiva, necessária e justa reação. (ROCHA, 1993, p. 51).

Além do acesso à Justiça, a ideia de cidadania perpassa também a nova abordagem do Estado Brasileiro: a Constituição de 1988 aponta para o desenho de um Estado Social, que tem como objetivo "incluir" grupos vulneráveis como indígenas idosos, crianças e adolescente; bem como cidadãos em situações geradores de necessidades (trabalhadores e seus dependentes quando diante da ausência de capacidade produtiva/ laboral e pessoas portadores de limitações físicas). ${ }^{14}$

\footnotetext{
14 "A questão que persiste é compreender e conscientizar os atores do campo político, jurídico e social que a política de direitos atende 'sujeitos de direitos' que não estão sendo 'beneficiados' pelo Estado, mas detém a capacidade de exercício destes direitos na ordem democrática, em uma perspectiva de cidadania inclusiva de indivíduos até recentemente 'invisíveis'." (XIMENES, 2015, p. 99).
} 
Contudo, não basta apenas a previsão normativa - direitos sociais demandam políticas públicas e consequentemente atuação do Poder Executivo, compromisso com a inclusão social. Até porque a cidadania inclusiva pressupõe o que Fraser (2001) aponta como as duas compreensões de injustiça: socioeconômica, enraizada na estrutura político-econômica da sociedade, como exploração do trabalho; e cultural ou simbólica, arraigada a padrões sociais de representação, interpretação e comunicação, como o não-reconhecimento e o desrespeito.

Dessa segunda perspectiva da cidadania surge o empoderamento - diante de situações de vulnerabilidade e de submissão, os indivíduos adquirem habilidade para buscar melhores condições de vida. ${ }^{15}$

Essas perspectivas são as premissas de análise do impacto da judicialização das políticas públicas de assistência social no exercício da cidadania inclusiva. A discussão sobre a legitimidade da atuação do Poder Judiciário não escamoteia as questões "simbólicas", implícitas, decorrentes do fenômeno?

César Rodriguez-Garavito (2011) aponta duas versões para a análise dos impactos da judicialização dos DESC, especialmente na América Latina. Para o autor, são duas abordagens: uma construtivista e outra neorrealista. Os neorrealistas se concentram nos efeitos diretos e palpáveis da decisão. Para estes autores o Direito é um conjunto de normas que molda a conduta humana, e assim aplicam relações de causalidade direta entre a decisão e o que é observável como resultado. Já para os construtivistas, o Direito e as decisões judiciais acarretam uma transformação social não apenas quando afetam mudanças na conduta de grupos e indivíduos diretamente envolvidos, mas também quando produz transformação indireta nas relações sociais ou quando provoca

15 O termo é frequentemente utilizado por movimentos de cunho emancipatório, relacionados ao exercício da cidadania como movimentos dos negros, das mulheres, dos homoafetivos, dos portadores de deficiência, dos idosos, etc., e "se refere ao processo de mobilização e práticas que objetivam promover e impulsionar grupos e comunidades na melhoria de suas condições de vida, aumentando sua autonomia". (KLEBA; WENDAUSEN, 2009). 
alteração na percepção social dos atores e legitima a compreensão dos litigantes. ${ }^{16}$ Nesse sentido, podemos refletir sobre a tabela a seguir:

\begin{tabular}{c|l|l}
\hline & \multicolumn{1}{|c|}{ Direto } & \multicolumn{1}{c}{ Indireto } \\
\hline Material & $\begin{array}{l}\text { Desenho da política } \\
\text { pública, como } \\
\text { determinado na } \\
\text { decisão }\end{array}$ & $\begin{array}{l}\text { Fomenta o debate influenciando a } \\
\text { articulação entre atores sociais e } \\
\text { políticos que passam a considerar a } \\
\text { temática em questão }\end{array}$ \\
\hline Simbólico & $\begin{array}{l}\text { Definição e percepção } \\
\text { do problema como } \\
\text { uma violação de } \\
\text { direitos }\end{array}$ & $\begin{array}{l}\text { Transforma a opinião pública sobre a } \\
\text { urgência e relevância do problema }\end{array}$ \\
\hline
\end{tabular}

Fonte: Adaptação de Rodriguez-Garavito (2011, p. 1679).

Aprofundando a percepção construtivista, o autor defende que é preciso uma ampliação de caráter metodológico nas atuais análises, incluindo técnicas qualitativas que possam captar os efeitos simbólicos, e aponta como, por exemplo, entrevistas com servidores públicos, ativistas e membros da sociedade para examinar o impacto da decisão na percepção individual dessas pessoas (RODRIGUEZ-GARAVITO, 2011, p. 1679).

Portanto, a questão do impacto indireto e simbólico vai além das questões quantitativas mensuráveis, incluindo fatores externos a percepção das pesquisas que têm sido feitas sobre a judicialização das políticas públicas. $\mathrm{O}$ debate pode ser também conduzido para analisar as lutas simbólicas por poder simbólico dentro do próprio campo jurídico, valorizando as representações dos diferentes atores segundo sua posição (por exemplo, o embate entre o posicionamento do Supremo e os juízes federais). Contudo, essa análise se concentra no campo jurídico sob a ótica interna; nossa abordagem amplia a reflexão para

16 "On the other hand, authors inspired by a constructivist conception of the relationship between law and society have criticized Rosenberg and the neorealists for focusing only on judgements' direct, material effects. According to these critics, law and judicial decisions generate social transformation not only when they induce changes in the conduct of the groups and individuals directly involved in the case, but also when they produce indirect transformations in social relations or when they alter social actors' perceptions and legitimize the litigants' worldview." (RODRIGUEZ-GARAVITO, 2011, p. 1678). 
a relação com o campo político, aqui representado basicamente pelo Poder Executivo no desenho da política pública. ${ }^{17}$

Quando recuperamos o significado de "dizer o direito", ou seja, da prestação jurisdicional, ampliamos o leque de funções dos tribunais, construindo um quadro conceitual e teórico que extravasa o domínio do litígio, incluindo as funções políticas e funções simbólicas dos tribunais (SANTOS et al., 1996). As funções políticas implicam na própria consciência de direitos e na afirmação da capacidade para os reivindicar, ou seja, uma forma de exercício da cidadania.

Na mesma linha de raciocínio, Luiz Roberto Cardoso de Oliveira (2010, p.457) aponta que "A dimensão simbólica, portanto, vai muito além daquilo que está expresso em qualquer código de direito, ou mesmo nos princípios formais que balizam os procedimentos e nas leis positivadas". O conceito busca trabalhar como os direitos são vividos e como ganham sentido para as partes, ou seja, o significado dos direitos.

\section{3. $O$ benefício de prestação continuada ${ }^{18}$}

Conforme aponta Rodriguez-Garavito (2011), através da análise e reflexão de casos é possível verificar impactos das decisões sobre os

17 Este é o motivo pelo qual o presente trabalho não utiliza as categorias teóricas de Bourdieu, pois como aponta Villegas (2010, p. 249): "Aunque éstos [derechos] generalmente operan para reforzar la legitimidade del Estado (eficácia simbólica), también tienen El potencial para que los movimentos sociales se aproprien de ellos y para servir como un arma política em contra del poder hegemônico" (VILLEGAS, 2010, p. 249), o que entretanto não inviabiliza outras abordagens sobre o mesmo caso, utilizando Bourdieu (ver BOURDIEU, Pierre. O poder simbólico. Rio de Janeiro: Bertrand, 1989). Conforme aponta Abramovich (2005, p.204), a judicialização e o "ativismo" nos DESC na América Latina e "está diretamente relacionada com a existência de fatores políticos que outorgaram ao Poder Judiciário uma especial legitimação para ocupar novos espaços de decisão, anteriormente restritos aos demais poderes do Estado".

18 Para conhecer mais sobre a judicialização do BPC ver: BICCA, Carolina Scherer. O "ativismo judicial" no controle das políticas públicas: o caso da Assistência Social no Brasil. Dissertação de Mestrado. Programa de Mestrado do Instituto Brasiliense de Direito Público. Brasília, 2011; PENALVA, Janaína; DINIZ, Débora; MEDEIROS, Marcelo. O benefício de prestação continuada no Supremo Tribunal Federal. Revista Sociedade e Estado, v. 25, n.1, jan./abr. 2010; SILVA, Naiane Louback da. A judicialização do Benefício de Prestação Continuada da Assistência Social. Serviço Social, n. 111, p. 555-575, jul./set 2012; SANTOS, Wederson Rufino dos. Deficiência e democracia: a interpretação do Poder Judiciário sobre o Benefício de Prestação Continuada. Dissertação de Mestrado. Universidade de Brasília, Programa Políticas Sociais, 2009; REIS, Maristela Alves dos. Uma análise da judicialização do Benefício de Prestação Continuada da Assistência Social (BPC) à luz da teoria dos diálogos institucionais. Monografia apresentada na Especialização em Gestão de Políticas Públicas de Proteção e Desenvolvimento Social. ENAP, 2013. 
DESC na América Latina que ultrapassam os efeitos materiais diretos, incluindo eventuais contribuições a arranjos democráticos.

No presente trabalho o caso analisado será o do Benefício de Prestação Continuada, o BPC. Trata-se de benefício da Política de Assistência Social, individual, constitucionalizado, com legislação infraconstitucional ${ }^{19}$ regulamentando sua concessão: a transferência mensal de um salário mínimo ao idoso com 65 anos ou mais, e à pessoa com deficiência, de qualquer idade, com impedimentos de longo prazo, de natureza física, mental, intelectual ou sensorial, que comprovem não possuir meios para prover a própria manutenção nem tê-la provida por sua família. Em ambos os casos a renda mensal bruta familiar per capita deve ser inferior a $1 / 4$ do salário mínimo vigente.

Em 1998, na Ação Direta de Inconstitucionalidade - ADI $n^{\circ}$ 1.232, o Supremo Tribunal Federal - STF entendeu que os critérios de elegibilidade para a concessão do benefício assistencial só poderiam ser fixados na esfera política. Contudo, vários cidadãos permaneceram em busca da concessão do BPC perante o Poder Judiciário. No caso concreto, embora a renda do requerente atingisse o patamar demeio salário mínimo, os magistrados identificavam condições econômicas precárias que exigiam a garantia do direito à assistência social, entendendo que, embora o critério de um quarto do salário mínimo tivesse sido declarado constitucional, conforme havia decidido o STF, esse critério não seria único.

Contra esse entendimento o INSS interpôs várias reclamações perante o STF, pugnando pela reforma de tais decisões. No julgamento da Reclamação $n^{\circ} 2.303$ o Supremo decidiu que o critério de renda de um quarto do salário mínimo seria único, consolidando o já definido legalmente e na ADI.

19 Lei Orgânica da Assistência Social - LOAS, Lei n 8.742/93 e Decretos n 6.214/2007 e 6.564/2008. 
Apesar da aparente definição no âmbito da interpretação, quando as condições concretas demonstravam a pobreza e a incapacidade para o trabalho, somadas a gastos adicionais advindos das condições precárias de saúde dos envolvidos, os magistrados continuaram concedendo o benefício mesmo quando a renda per capita familiar ultrapassava o patamar de um quarto do salário mínimo.

A demanda individual nos Juizados Especiais Federais quanto aos critérios de concessão a partir do caso concreto resultou ainda na Súmula n. 11 de 2004 da Turma Nacional de Uniformização da Jurisprudência dos Juizados Especiais Federais, cancelada em 24/04/2006. ${ }^{20}$

Entretanto, com base em legislações posteriores que garantiam o direito à assistência social utilizando o critério de renda per capita de meio salário mínimo, o STF passou a rever seu posicionamento. Essa mudança interpretativa culminou no reconhecimento da repercussão geral em um recurso extraordinário em que o benefício foi concedido a cidadão com renda superior ao limite legal. Em 2013 o STF decidiu que o critério era inconstitucional, deixando para o campo política a definição e regulamentação de um novo critério. ${ }^{21}$

Apesar da discussão sobre o eventual ativismo judicial por parte do Poder Judiciário, é interessante notar que o BPC está atingindo famílias extremamente pobres, e não pobres, mas isso não tem sido um obstáculo na defesa de seus direitos e na tentativa de inclusão em uma

20 "A renda mensal, "per capita", familiar, superior a $1 / 4$ (um quarto) do salário mínimo não impede a concessão do benefício assistencial previsto no art. 20 , § 3o, da Lei $8.742 / 93$, desde que comprovada, por outros meios, a miserabilidade do postulante." Precedentes: REsp 222.764/SP, REsp 222.777/SP, REsp 222.778/SP, REsp 288.742/SP, REsp 397.943/SP, REsp 327.836/SP, REsp 435.871/SP, AgRg no Ag 311. 369/SP, AgRg no Ag 419.145/SP

21 Reclamação 4374/PE e os Recursos Extraordinários 567985 e 580963 , ambos com repercussão geral. O Plenário, por maioria dos votos, declarou a inconstitucionalidade do $\S 3^{\circ}$, do art. 20 da LOAS (que estabelece o critério de $1 / 4$ do salário mínimo), por considerar que esse critério está defasado para caracterizar a situação de miserabilidade do indivíduo e de sua família. 
política social que está utilizando um patamar de renda que não satisfaz necessidades básicas de alimentação, vestimenta e habitação. ${ }^{22}$

E de fato, 16,88\% dos benefícios foram concedidos judicialmente em 2014 - 44.525 para pessoas com deficiência e 13.594 para idosos. Ou seja, 58.219 indivíduos só conseguiram acesso ao benefício através do litígio, que permite uma análise de suas reais condições de vida e assim altera a forma como a política pública é interpretada. ${ }^{23} \mathrm{Em} 2004$, o percentual de judicialização do BPC era de 2,57\%, o que demonstra que em 10 anos, os sujeitos de direitos perceberam no Poder Judiciário como um canal para solicitar a alteração na política pública. (SUIBE/ DATAPREV, 2015).

E aqui mais um elemento importante na argumentação do efeito simbólico da judicialização (ou a ausência de impacto): a atuação do Conselho Nacional de Assistência Social (CNAS).

As demandas judiciais iniciadas junto aos juizados especiais federais chegaram ao STF por meio de interposição de recursos. Em abril de 2005, no julgamento do Agravo Regimental na Reclamação 2.3036/RS, de relatoria da Ministra Ellen Gracie, o Tribunal deu provimento à Reclamação argumentando que a sentença impugnada afrontava o posicionamento daquela Corte adotado a partir do julgamento da ADI 1.232. Na oportunidade, o Ministro Ayres Britto proferiu seu voto

22 O critério atual de renda familiar per capita inferior a um quarto do salário mínimo carece de base técnica. Sua fundamentação não tem origem nos princípios constitucionais que guiam a assistência social no Brasil. Se o objetivo do BPC é proteger famílias pobres que não são capazes de prover o sustento de seus membros, o valor de menos de um quarto do salário mínimo per capita é incorreto. Todas as linhas de pobreza brasileiras são superiores a esse montante. Além disso, como a lei determina renda "inferior", e não "igual ou inferior" a um quarto do salário mínimo, na prática, isso exige que boa parte das famílias tenha renda bem inferior a um quarto do salário mínimo para serem legalmente elegíveis. (PENALVA; DINIZ; MEDEIROS, 2010, p. 65).

23 Para o propósito do presente trabalho, não analisaremos o efeito perverso do acesso à Justiça - o percentual de pessoas que não conseguem acesso ao Poder Judiciário, principalmente considerando as desigualdades regionais no Brasil. Boaventura de Sousa Santos (1997, p. 3965) aponta que três dimensões de dificuldades de acesso à Justiça: econômica, social e cultura. A Justiça é cara, nem todos conhecem seus direitos e alguns não acreditam no seu potencial. 
utilizando-se de argumentos favoráveis às posições adotadas no âmbito dos juizados especiais federais:

Em outras palavras - e como tudo na vida comporta leitura ora mais ora menos subjetiva -, entendo que o juiz singular nem se contrapôs por modo frontal ao nosso decisum, nem proferiu julgamento insuscetível de assimilação por esse decisum mesmo. O que enxergo no ato sentencial ora invectivado é a consubstanciação de valores e critérios francamente assimiláveis pela decisão plenária tido por violada $[\ldots]^{24}$

A Constituição de 1988 prevê um sistema descentralizado e participativo na definição e condução de políticas públicas da Assistência Social ${ }^{25}$. A participação será feita a partir do Conselho Nacional de Assistência Social (CNAS), órgão superior de deliberação colegiada, composto por 18 membros que representam o governo e a sociedade civil, com mandato de 2 anos. Os representantes da sociedade civil são escolhidos em foro próprio, sob fiscalização do Ministério Público Federal, dentre representantes dos usuários ou de organizações de usuários, das entidades e organizações de assistência social e dos trabalhadores do setor.

O texto constitucional e a legislação infraconstitucional reforçam o caráter participativo do CNAS na definição e implementação das políticas públicas de assistência social.

Contudo, as deliberações das Conferências Nacionais de Assistência Social indicam que, desde 1995, a necessidade de alteração do critério para concessão do benefício estava presente, inclusive com

24 Ag. Reg. Reclamação 2.303-6/ RS.Relatora Ministra Ellen Gracie, Agravante: Patrícia Costa Diogo, Agravado: INSS. Voto-vista Ministro Carlos Ayres Britto, p. 117-126. Disponível em: <http:// redir.stf.jus.br/paginadorpub/paginador.jsp?docTP=AC\&docID=361858> . Acesso em: 7 jul. 2013.

25 Lei n. 8.742/93 (LOAS), art. 6o. As ações na área de assistência social são organizadas em sistema descentralizado e participativo, constituído pelas entidades e organizações de assistência social abrangidas por esta lei, que articule meios, esforços e recursos, e por um conjunto de instâncias deliberativas compostas pelos diversos setores envolvidos na área. 
divergência sobre o novo critério, 1/2 ou o salário mínimo integral, conforme demonstra a tabela abaixo.

\begin{tabular}{|c|c|c|c|}
\hline & DATA & DELIBERAÇÃO & DELIBERAÇÃO \\
\hline I CNAS & $\begin{array}{l}20-23 \text { nov. } \\
1995\end{array}$ & $\begin{array}{l}\text { Ampliar o alcance do BPC pela alteração } \\
\text { limite da renda mensal familiar per } \\
\text { capita, que deve ser limitada a um salário } \\
\text { mínimo e não a } 1 / 4 \text { do salário mínimo. }\end{array}$ & $\begin{array}{l}\text { Sem deliberação em } \\
\text { Resolução. }\end{array}$ \\
\hline II CNAS & $\begin{array}{l}9 \mathrm{~d} \text { e z } \\
1997\end{array}$ & $\begin{array}{l}\text { Alterar a renda per capita de } 1 / 4 \text { para } 1 / 2 \\
\text { salário mínimo }\end{array}$ & $\begin{array}{l}\text { Sem deliberação em } \\
\text { Resolução. }\end{array}$ \\
\hline III CNAS & $\begin{array}{l}04-07 \text { dez. } \\
2001\end{array}$ & $\begin{array}{l}\text { Elevação da renda familiar para } 1 \text { salário } \\
\text { mínimo conforme projeto de lei que } \\
\text { tramita na Comissão de Constituição e } \\
\text { Justiça na Câmara Federal (PL 3055/99) }\end{array}$ & $\begin{array}{l}\text { Sem deliberação em } \\
\text { Resolução. }\end{array}$ \\
\hline IV CNAS & $\begin{array}{l}7-10 \mathrm{dez} . \\
2003\end{array}$ & $\begin{array}{l}\text { Alterar os critérios para concessão do } \\
\text { BPC estabelecendo a renda per capta } \\
\text { de } 1 / 2 \text { salário mínimo para o acesso. }\end{array}$ & $\begin{array}{l}\text { Resolução CNAS } n^{\circ} \\
\text { 30, de } 1 \text { de março de } \\
2004 .\end{array}$ \\
\hline V CNAS & $\begin{array}{l}5-8 \mathrm{dez} . \\
2005\end{array}$ & $\begin{array}{l}\text { Rever as regulamentações do BPC } \\
\text { quanto a alteração do critério de renda } \\
\text { per capita familiar de } 1 / 4 \text { para } 1 / 2 \text { salário } \\
\text { mínimo a curto prazo e de } 1 \text { salário } \\
\text { mínimo a longo prazo }\end{array}$ & $\begin{array}{l}\text { Resolução CNAS } n^{\circ} \\
40 \text {, de } 16 \text { de fevereiro } \\
\text { de } 2006 .\end{array}$ \\
\hline VI CNAS & $\begin{array}{l}14-17 \text { dez. } \\
2007\end{array}$ & $\begin{array}{l}\text { Equiparar as regras do BPC para as } \\
\text { pessoas com deficiência com aquelas } \\
\text { aplicadas ao idoso, não computando o } \\
\text { valor do benefício já concedido ao idoso } \\
\text { ou à pessoa com deficiência, no cálculo } \\
\text { da renda per capita familiar para fins de } \\
\text { acesso de outro membro da família }\end{array}$ & $\begin{array}{l}\text { Resolução CNAS } n^{\circ} \\
42 \text {, de } 10 \text { de março } \\
\text { de } 2008 .\end{array}$ \\
\hline VII CNAS & $\begin{array}{l}30 \text { nov. } / 3 \\
\text { dez. } 2009\end{array}$ & $\begin{array}{l}\text { Ampliar o critério de concessão do } \\
\text { benefício quanto a exigência de renda } \\
\text { per capita de } 1 / 4 \text { para } 1 / 2 \text { salário mínimo }\end{array}$ & $\begin{array}{l}\text { Resolução CNAS } n^{\circ} \\
105 \text { de } 3 \text { de dezembro } \\
\text { de } 2009 .\end{array}$ \\
\hline VIII CNAS & $\begin{array}{l}07-10 \text { dez. } \\
2011\end{array}$ & $\begin{array}{l}\text { Propor alteração do art. } \mathrm{n}^{\circ} 20 \text { da Lei } \mathrm{n}^{\circ} \\
8.742 / 93 \text { (LOAS) quanto aos critérios } \\
\text { para acesso ao BPC, estabelecendo } \\
\text { valor mínimo da renda per capta para o } \\
\text { acesso em meio salário mínimo. }\end{array}$ & $\begin{array}{l}\text { Resolução CNAS } n^{\circ} \\
1 \text {, de } 9 \text { de janeiro de } \\
2012 .\end{array}$ \\
\hline
\end{tabular}

Fonte: Tabela elaborada pela autora a partir do documento. Disponível em: <www.mds.gov. br>

Assim, não apenas a judicialização indicava a necessidade de alterar o critério de concessão do benefício, mas a própria participação social nas conferências nacionais. Isto demonstra o distanciamento 
do responsável pela política pública do sujeito de direito, cuja única alternativa é a judicialização.

Nesse caso específico, a judicialização parece ser uma forma de empoderamento do sujeito de direito que durante anos não foi ouvido pela política pública de assistência social. Em que medida a judicialização possui justamente o efeito simbólico de perceber o cidadão como titular de direito e assim demandar prestações e condutas?

A decisão sobre o patamar de renda é uma decisão política, mas considerando o contexto da desigualdade brasileira e o Estado Social imposto pela Constituição de 1988, a judicialização parece permitir "voz" e "visibilidade" aos "invisíveis".

\section{Efeitos simbólicos da judicialização do BPC}

A partir da última problematização, utilizando a grade de leitura de Rodriguez-Garavito (2011), propomos uma reflexão sobre os impactos simbólicos da judicialização do BPC.

Rodriguez-Garavito (2011) desenha referenciais para o que chama de "ativismo dialógico" através de dois mecanismos institucionais: a) as decisões dialógicas determinam claros caminhos de implementação através de metas e apresentação de relatórios, deixando para as agências governamentais decisões mais substanciais; b) as decisões dialógicas influenciam mecanismos participativos após a decisão como audiências públicas, comissões de monitoramento, envolvimento da sociedade civil em discussões por parte do governo. ${ }^{26}$

26 "I argue that impact is likely to be higher when courts engage in 'dialogic activism' through two institutional mechanisms. First, dialogic rulings set broad goals and clear implementation paths through deadlines and progress reports, while leaving substantive decisions and detailed outcomes to government agencies. Orders of this nature are not only compatible with the separation of powers principle but also can bolster the overall efficacy of a given decision. Second, a dialogic approach to SER cases encourages participatory follow-up mechanisms-public hearings, courtappointed monitoring commissions, and invitations to civil society and government agencies to submit relevant information and participate in court-sponsored discussions-which both deepen democratic deliberation and enhance the impact of court interventions." (RODRIGUEZGARAVITO, 2011, p. 1676). 
Ao reiteradamente aceitar os recursos das decisões negando o benefício pelo INSS, a Justiça Federal tem aprovado uma mudança no rumo da política pública: aparentemente ela foi desenhada para os extremamente pobres, mas aumentando de $1 / 4$ para um salário mínimo incluiria os pobres.

Uma hipótese levantada por Rodriguez-Garavito (2011) aponta também no sentido aqui proposto: decisões dialógicas têm um maior impacto porque afetam dois obstáculos principais na implementação de uma decisão estrutural: resistência política e capacidade institucional. ${ }^{27}$ Conforme já apontado no caso do BPC, os poderes políticos não se manifestaram quanto às reiteradas decisões judiciais, nem mesmo diante das resoluções da CNAS.

Assim, nesse caso específico, não há como mensurar efeitos indiretos de forma dialógica como a proposta pelo autor. Contudo, sob a perspectiva simbólica da atuação da cidadania, a continuidade na demanda perante o Poder Judiciário, apesar de decisões que teoricamente delimitam mais a interpretação do magistrado de primeiro grau, reflete uma alternativa ao mecanismo do voto para o novo desenho da política pública em questão, atendendo um maior número de pessoas em situação de vulnerabilidade.

Nesta linha de raciocínio, a judicialização tem sido utilizada por esta parcela da população como estratégia para reivindicar um benefício assistencial constitucionalmente previsto para cidadãos altamente vulneráveis.

Na linha do que Rodriguez-Garavito (2011) desenvolve em seu trabalho, o impacto simbólico pode ser abordado sob duas perspectivas:

1 - Para o cidadão, titular do direito, diante do distanciamento do responsável pela política pública de seu direito, a judicialização

\footnotetext{
27 "I hypthesize that dialogic rulings have greater impact because they address the two key practical obstacles to the implementation of structural decisions: political resistance and institutional capacity" (RODRIGUEZ-GARAVITO, 2011, p. 1695).
} 
acarreta o empoderamento, a busca não pelo reconhecimento, mas pela efetivação deste direito;

2 - Para o arranjo democrático o impacto simbólico reside na provocação por intermédio da judicialização deste mesmo distanciamento. Mesmo com a manifestação da CNAS, a política pública não foi alterada, o que só ocorrerá agora, com a decisão no STF.

Apesar de não ser função típica do Poder Judiciário definir políticas públicas e exercer o papel de "protagonista de transformação social" (SOUZA NETO, 2012, p. 35), e esta nem é a hipótese aqui levantada, ele pode influenciar de outras formas, principalmente procurando preservar a integridade democrática entre cidadãos a partir do diálogo. ${ }^{28}$ Gloppen (2006, p. 38) argumenta:

Social transformation can be defined as the altering of structured inequalities and power relations in society in ways that reduce the weight of morally irrelevant circumstances, such as socio-economic status/class, gender, race, religion or sexual orientation. Courts' transformation performance is their contribution to the altering of such structured inequalities and power relations, or in other words, whether they serve as an institutional voice for the poor and contribute to the social inclusion of disadvantaged and marginalized groups. Which groups are the most vulnerable and marginalized varies between societies, depending on the structure and depth of social inequalities.

Assim, o eventual impacto que o Judiciário pode ter na transformação social e na inclusão de grupos "marginalizados" - se de

28 Por outro lado, isso não quer dizer que o Judiciário não possua um papel fundamental no regime democrático. A história está repleta de exemplos que levam à conclusão de que a democracia não pode ser entendida apenas a partir do princípio majoritário. A democracia implica, além da decisão majoritária, também a instauração de um contexto de diálogo, de respeito pela posição do outro e de garantia dos direitos fundamentais das minorias. É justamente na promoção desse contexto e na garantia desses direitos que o Judiciário pode desempenhar um papel primordial. $\mathrm{O}$ Judiciário pode ser, nessa linha, um guardião da democracia. Por isso, só há sentido em pensar em uma "judicialização da política" enquanto atuação judicial que preserve a interação democrática entre os cidadãos, e não como realização pelo Judiciário de tarefas que legitimamente cabem às maiorias. (SOUZA NETO, 2012, p. 36) 
alguma forma circunstâncias como classe social, sexo, gênero, religião e orientação sexual deixam de ter um peso significativo na desigualdade e nas relações de poder, ao conceder voz para os pobres e grupos marginalizados.

Abramovich (2006) registra que a judicialização não é fruto das necessidades dos titulares dos direitos, mas de "sujeitos de direitos" que demandam prestações e condutas. Assim, três objetivos podem ser alcançados após o reconhecimento dos direitos e eventualmente com a sua judicialização: inclusão, participação e responsabilidade (aqui no âmbito das políticas públicas).

Portanto, no contexto de um Estado Social e sua lógica específica e da necessidade de efetivação dos direitos sociais em um país com altos índices de desigualdade socioeconômica, a perspectiva da inclusão e participação precisa ser abordada pelos diferentes atores do campo politico, jurídico e social.

O presente trabalho busca abordar a própria judicialização das políticas públicas por cidadãos que não conseguem "se enxergar" no arranjo democrático, confiando no Poder Judiciário a alteração de uma decisão governamental que os afeta profundamente. Em que medida a prática social de judicializar não permite uma análise positiva sobre a participação do cidadão na democracia brasileira, ainda que não utilizando os mecanismos convencionais de participação popular?

A hipótese é a necessidade de compreensão dos direitos a partir de uma lógica em que prevaleça a cidadania "inclusiva", atentando para a internalização de valores (OLIVEIRA, 2011) que viabilizem uma transformação na orientação das ações ou atitudes dos atores em suas práticas cotidianas efetivando os direitos sociais. Considerando esta perspectiva cidadã dos direitos sociais é possível abordar a judicialização das políticas públicas atrelada à democracia na política pública de assistência social do BPC.

Considerando ainda a necessária discussão mais ampla sobre o papel das políticas de solidariedade nacional na garantia de rendas 
mínimas nas diversas situações de vulnerabilidade social e pobreza, a alteração na política pública perpassa ainda a compreensão de sujeitos de direitos e não de "necessitados" ou de "caridade". ${ }^{29}$

A partir da análise aqui desenvolvida sobre o BPC, é possível concluir que a litigância fortifica a cidadania inclusiva. E isso é consistente com o Estado Social estabelecido no texto constitucional, não apenas pela redistribuição, mas também pelo reconhecimento e inclusão. Os "beneficiários" precisam se enxergar como sujeitos de direitos, como cidadãos e assim serem "vistos" pelos atores dos campos político e social. $^{30}$

\section{Conclusão}

O presente trabalho apresentou uma preocupação com a pesquisa jurídica: esta tem se preocupado predominantemente com os impactos materiais e diretos da judicialização das políticas públicas, esquecendo os impactos indiretos e simbólicos. Isto porque nos países da América Latina a desigualdade é uma premissa e muitas vezes não há cultura política forte o suficiente para a efetivação de direitos sociais conquistados apenas no papel.

Apesar das discussões sobre o fenômeno da judicialização das políticas públicas, especialmente sob a perspectiva da legitimidade

29 "A hipótese que sustenta a argumentação é a de que no Brasil, a pobreza de parcelas significativas da população e a extrema desigualdade que vem marcando a sociedade, colocam importantes dificuldades para a ampliação da coesão social e para a reprodução da estabilidade e legitimidade do regime democrático" (JACCOUD, 2009, p. 3). A autora destaca ainda que "O cerne desse debate se refere à questão da integração social nas sociedades modernas, ancoradas de um lado na centralidade do trabalho e na criação de riquezas, e, de outro, na igualdade política e civil dos indivíduos" (p. 19-20).

30 Rego (2008, p.162) explica que: "É bom lembrar que a democratização crescente da cidadania não significa apenas uma compreensão normativa do seu forte potencial integrativo e igualitário. Supõe, de um lado, a consecução de políticas de crescente reconhecimento por parte do Estado da legitimidade do conflito e das lutas por direitos. E, de outro, que as políticas de renda, ou as políticas distributivas em sentido geral, tenham seu fundamento fortemente fincado no princípio da cidadania, no cidadão como titular inalienável de direitos. Apenas de não ser sido judicializado, a proposta de análise sobre o Bolsa Família a partir dos sujeitos de direitos se aproxima a logica utilizada neste trabalho. 
democrática e das dificuldades financeiras que as decisões acarretam, pouco se discute a dimensão cidadã da problemática. Em que medida a judicialização concede "voz" aos "invisíveis"? Este foi o problema apresentado neste trabalho utilizando como parâmetro a judicialização do BPC.

É necessário discutir o empoderamento do direito (acesso ao direito) pela sociedade como via de colaboração à função jurisdicional, buscando práticas emancipadoras e o exercício da cidadania no cotidiano, nas práticas sociais. Mais do que acesso à Justiça, a judicialização das políticas públicas é um desafio para a efetivação da cidadania "inclusiva", atentando para a internalização de valores que viabilizem uma transformação na orientação das ações ou atitudes dos atores em suas práticas cotidianas efetivando os direitos fundamentais.

A partir da análise do caso BPC, demonstrou-se que a judicialização está alterando a política pública de forma positiva, considerando que uma maior parcela da população em situação de vulnerabilidade está sendo alcançada, ainda que as deliberações do CNAS não tenham tido este mesmo impacto.

Portanto, no caso aqui analisado, o relevante efeito simbólico foi o reforço aos sujeitos de direitos no âmbito da atuação institucional dos outros dois poderes, especialmente o Executivo, responsável pelo desenho da política pública. ${ }^{31}$

Obviamente que as conclusões aqui apresentadas não podem ser generalizadas para outros direitos sociais, pois o risco da "cidadania clientelista" apontado anteriormente persiste. Contudo, apesar dos avanços dos últimos anos no tocante a efetivação de direitos sociais

31 Rodriguez-Garavito (2011, p.1676) salienta ainda que a temática passa a ser considerada como um problema de direitos humanos: "Based on case study evidence, I posit that the potential range of relevant effects includes-in addition to governmental action specifically mandated by the court-the reframing of socioeconomic issues as human rights problems, the strengthening of state institutional capacities to deal with such problems, the forming of advocacy coalitions to participate in the implementation process, and the promoting of public deliberation and a collective search for solutions on the complex distributional issues underlying structural cases on SERs." 
por intermédio de políticas públicas, é preciso reconhecer os sujeitos de direitos, especialmente nas políticas de assistência social e a sua movimentação para a efetivação dos seus direitos. Esta foi a perspectiva do presente trabalho. O efeito simbólico da judicialização do BPC, como transformação social, é o empoderamento dos "invisíveis": sob a perspectiva da cidadania inclusiva, o cidadão está tendo "voz" no Poder Judiciário.

\section{Referências}

ABRAMOVICH, Victor. Linhas de trabalho em direitos econômicos, sociais e culturais: instrumentos e aliados. Revista Internacional de Direitos Humanos, São Paulo, ano 2, n. 2, p. 188-223, 2005.

. Una aproximación al enfoque de derechos en las estrategias y políticas de desarrollo. Revista de la CEPAL, Vitacura, n. 88, p. 35-50, abr. 2006.

ECONOMIDES, Kim. Lendo as ondas do "Movimento de acesso à justiça": epistemologia versus metodologia? In: PANDOLFI, Dulce et al (Org.). Cidadania, justiça e violência. Rio de Janeiro: Fundação Getúlio Vargas, 1999. p. 61-76.

EWALD, François. A concept of law. In: TEUBNER, Gunther. Dilemmas of law in the Welfare State. Berlin/New York: Gruyter, 1985. p. 40-75.

FERRA, Octavio Luiz Motta. Harming the poor through social rights litigation: lessons from Brazil. Texas Law Review, Austin, v. 89, p. 1643-1668, 2011.

FRASER, Nancy. Da redistribuição ao reconhecimento? Dilemas da justiça na era pós-socialista. In: SOUZA, Jessé. Democracia hoje: novos desafios para a teoria democrática contemporânea. Brasília: UnB, 2001. p. 245-282.

GALDINO, Flávio. Introdução à teoria dos custos dos direitos: direitos não nascem em árvores. Rio de Janeiro: Lumen Juris, 2005. 
GARAPON, Antoine. O juiz e a democracia. 2. ed. Rio de Janeiro: Revan, 2001.

GLOPPEN, Siri. Courts and social transformation: an analytical framework. In: GARGARELLA, Roberto; DOMINGO, Pilar; ROUX, Theunis. Courts and social transformation in new democracies: an institutional voice for the poor? Hampshire: Ashgate, 2006. p. 35-59.

GONÇALVES, Alcindo. Políticas públicas e a ciência política. In: BUCCI, Maria Paula Dallari. Politicas públicas: reflexões sobre o conceito jurídico. São Paulo: Saraiva, 2006. p. 75-96.

KLEBA, Maria Elisabeth; WENDAUSEN, Agueda. Empoderamento: processo de fortalecimento dos sujeitos nos espaços de participação social e democratização política. Saúde Sociedade, São Paulo, v. 18, n. 4, p. 733-743, 2009.

KRELL, Andreas J. Direitos sociais e controle judicial no Brasil e na Alemanha. Porto Alegre: Sergio Antonio Fabris Editor, 2002.

JACCOUD, Luciana. Pobres, pobreza e cidadania: os desafios recentes da proteção social. In: Texto para Discussão, Brasília: IPEA, 2009. p. 1-32. (Série Seguridade Social - Texto para discussão n. 1372).

LOPES, José Reinaldo de Lima. Direitos sociais: teoria e prática. São Paulo: Método, 2006.

MAUS, Ingeborg. Judiciário como superego da sociedade - o papel da atividade jurisprudencial na "sociedade órfã". Novos Estudos CEBRAP, São Paulo, n. 58, p. 183-202, nov. 2000.

OLIVEIRA, Luís Roberto Cardoso de. A dimensão simbólica dos direitos e a análise de conflitos. Revista de Antropologia, São Paulo, USP, v. 53, n. 2, p. 451-473, 2010.

PENALVA, Janaína; DINIZ, Débora; MEDEIROS, Marcelo. O benefício de prestação continuada no Supremo Tribunal Federal. Revista Sociedade e Estado, Brasília, v. 25, n. 1, p. 53-70, jan./abr. 2010. 
REGO, Walquiria Leão. Aspectos teóricos das políticas de cidadania: uma aproximação ao bolsa família. Lua Nova, São Paulo, v. 73, p. 147-185, 2008.

REGO, Walquiria Leão; PINZANI, Alessandro. Vozes do bolsa família: autonomia, dinheiro e cidadania. São Paulo: UNESP, 2013.

ROCHA, Carmen Lúcia. O direito constitucional à jurisdição. In: TEIXEIRA, Sálvio de Figueiredo (Coord.). As garantias do cidadão na justiça. São Paulo: Saraiva, 1993. p. 31-51.

RODRIGUEZ-GARAVITO, César. Beyond the courtroom: the impact of judicial activism on socioeconomic rights in Latin America. Texas Law Review, Austin, v. 89, p. 1669-1698, 2011.

SHAPIRO, Martin; STONE, Alec Sweet. The new constitutional politics of Europe. Comparative Political Studies, v. 26, n. 4, p. 397-420, jan. 1994.

SOUSA SANTOS, Boaventura et al. Os tribunais nas sociedades contemporâneas: o caso português. Porto: Afrontamento, 1996.

SOUZA NETO, Cláudio Pereira de. Teoria da constituição, democracia e igualdade. Disponível em: <http://www.mundojuridico. adv.br/cgi-bin/upload/texto1129(3). pdf>. Acesso em: 12 dez. 2012.

STRECK, Lênio Luiz. Verdade e consenso. 4. ed. São Paulo: Saraiva, 2011.

VÁZQUEZ, Daniel; DELAPLACE, Domitille. Políticas púbicas na perspectiva de direitos humanos: um campo em construção. SUR, São Paulo, n. 8, n. 14, p. 35-65, jun. 2011.

VALLE, Vanice Regina Lírio do. Políticas públicas, direitos fundamentais e controle judicial. Belo Horizonte: Fórum, 2009.

VILLEGAS, Maurício Garcia; RODRIGUEZ, César. Derecho y sociedad en América Latina: propuesta para la consolidación de los estudios jurídicos críticos. In: VILLEGAS, Maurício Garcia; RODRIGUEZ, César. Derecho y sociedad en América Latina: un 
debate sobre los estúdios jurídicos críticos. Bogotá: ILSA, 2003. p. 1566 .

VILLEGAS, Maurício García. Sociología y crítica del derecho. Mexico: Fontamara, 2010.

VIEIRA, Oscar Vilhena. A desigualdade e a subversão do Estado de Direito. Revista Internacional de Direito e Cidadania, Erechim, n. 1, p. 185-201, jun. 2008.

XIMENES, Julia Maurmann. Direitos sociais e campo jurídico sujeitos de "direitos" e não de "necessidades" In: XIMENES, Julia Maurmann (Org.). Judicialização dos direitos sociais e seu impacto na democracia. Brasília: IDP, 2014. p. 81- 100. e-book. Disponível em: <www.idp.edu.br> Acesso em: 12 mar. 2016.

Recebido em: 11/05/2015

Aprovado em: 10/12/2015 